Schweizerische Gesellschaft für Dermatologie und Venereologie Société Suisse de Dermatologie et de Vénéréologie Colloquium Dermatologicum Aarau, den 30. April 1950

Dermatologica. 1950;101:243

\title{
Zur Behandlung der Pityriasis rosea Giberti
}

J.

Walch

Zürich

Die bereits im Handbuch kurz angedeutete Methode der Behandlung der Pityriasis rosea Giberti mit U. V.-Bestrahlung wurde an einei Reihe von Patienten ausprobiert. Alle Fälle reagierten schon in kürzester Zeit, zum Teil bereits nach einer einzigen Bestrahlung, recht deutlich durch Abnahme des Juckreizes und Verblassen der Effloreszenzen.

Es wurde aus $1 \mathrm{~m}$ Abstand, beginnend mit 1 Minute und Wieder-holung alle 2-3 Tage, bestrahlt. Eine Lokaltherapie ist nicht not-wendig; bei empfindlicher Haut kann die Abschuppung mit Borcold-cream eventuell angenehmer gestaltet werden. Exacerbationen wur-den keine beobachtet.

Die Krankheitsdauer ist sicher kürzer als bei der Spontanheilung. Im Vergleich zur ebenfalls rasch wirkenden Wismuth-Behandlung hat die Methode den Vorteil, daß keine Injektionen verabfolgt werden müssen. 